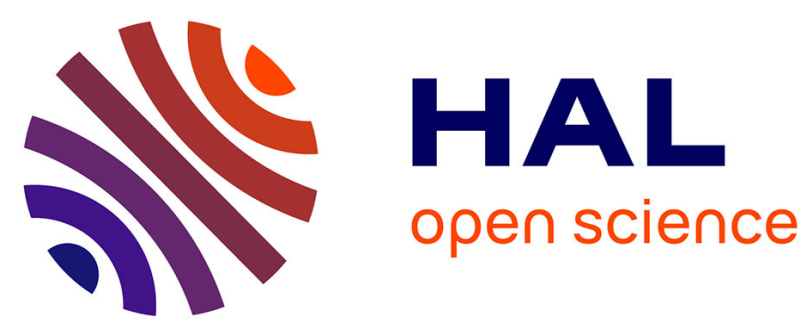

\title{
Feasibility study of fissile mass quantification by photofission delayed gamma rays in radioactive waste packages using MCNPX
}

Eric Simon, Fanny Jallu, Bertrand Perot, Stéphane Plumeri

\section{To cite this version:}

Eric Simon, Fanny Jallu, Bertrand Perot, Stéphane Plumeri. Feasibility study of fissile mass quantification by photofission delayed gamma rays in radioactive waste packages using MCNPX. Nuclear Instruments and Methods in Physics Research Section A: Accelerators, Spectrometers, Detectors and Associated Equipment, 2016, 840, pp.28-35. 10.1016/j.nima.2016.09.047 · cea-01992404

\section{HAL Id: cea-01992404 https://hal-cea.archives-ouvertes.fr/cea-01992404}

Submitted on 4 Dec 2019

HAL is a multi-disciplinary open access archive for the deposit and dissemination of scientific research documents, whether they are published or not. The documents may come from teaching and research institutions in France or abroad, or from public or private research centers.
L'archive ouverte pluridisciplinaire HAL, est destinée au dépôt et à la diffusion de documents scientifiques de niveau recherche, publiés ou non, émanant des établissements d'enseignement et de recherche français ou étrangers, des laboratoires publics ou privés. 


\title{
1 Feasibility study of fissile mass quantification by photofission \\ 2 delayed gamma rays in radioactive waste packages using MCNPX
}

3 Eric Simon ${ }^{a^{*}}$, Fanny Jallu $^{\mathrm{a}}$, Bertrand Pérota ${ }^{\mathrm{a}}$, Stéphane Plumeri ${ }^{\mathrm{b}}$

4

5

6

7

a CEA, DEN, Cadarache F-13108 Saint Paul Lez Durance cedex, France

b Andra, 1-7 rue Jean Monnet, F-92298 Chatenay-Malabry, France

\section{*Corresponding author : eric.simon@cea.fr}

Keywords: Photofission, Radioactive waste package, MCNPX, Uranium

\begin{abstract}
The feasibility of fissile mass quantification in large, long-lived medium activity radioactive waste packages using photofission delayed gamma rays has been assessed with MCNPX. The detection limit achievable is lower than the expected uranium mass in these waste packages, but the important sensibility to the waste matrix density and sample localization imposes to get an accurate measurement of these parameters. An isotope discrimination method based on gamma-ray ratios has been evaluated showing that photofission delayed gamma rays can be used to measure the fissile mass as well as the total uranium mass.
\end{abstract}

\section{Introduction}

An important issue in the management of nuclear waste repository is the characterization of radioactive waste packages. Waste characteristics are to be compliant with specifications of the French National Radioactive Waste Management Agency (Andra) before disposal to ensure the waste repository safety. Many non-destructive methods have been studied on large waste packages to address this characterization. Among them, active interrogation methods have shown promising results to quantify the global mass of actinides or the fissile mass present in dense, potentially heterogeneous packages, either using incident neutrons or high energy photons. Depending on the type of waste packages, these methods are more or less efficient, being mainly sensitive to different parameters like hydrogen content of the matrix for neutrons or density and effective atomic number for photons.

Active neutron interrogation has been successfully applied onto medium sized waste (maximum 220L) packages [1][2][3][4], but larger packages having a dense, hydrogenated matrix cannot be accurately examined by neutron interrogation followed by the detection of fission neutrons because of unacceptable uncertainties due to high and variable attenuation. For instance, the poor knowledge of hydrogen concentration in $1 \mathrm{~m}^{3}$ concrete packages would introduce decades of uncertainties on the fissile mass when it is heterogeneously distributed in the waste. Previous methods [7] have been investigated using delayed neutron from photofission but suffer from similar drawbacks with outgoing neutron attenuation. The preferred method is then to use an incident high energy photon beam to produce photofission in actinides and to measure delayed gamma rays [5][6]. We present here a feasibility study of uranium quantification in 870L radioactive produced by CEA [8] waste packages having a hydrogenated matrix and heterogeneous waste, by detection of photofission delayed gamma rays. This study has been 
performed using the Monte Carlo code MCNPX 2.7.0 [9]. The study was carried out by first designing the examination geometry, and then by assessing the passive and active backgrounds in view to determine the detection limits of uranium mass for the main delayed gamma rays of interest.

The simulated measurements are performed with high resolution HPGe gamma detector in view to analyze the different delayed gamma rays following photofission of $235 \mathrm{U}$ and ${ }^{238} \mathrm{U}$ isotopes. Due to GDR (Giant Dipolar Resonance) photofission cross section behavior, both actinides of odd and even mass numbers may be subject to photofission. Uranium content is first investigated thanks to its known nuclear photofission data [10]. The other key element in the waste packages, plutonium, still lacks reliable nuclear photofission data and could be assessed in the same way once these data are completed. The effects of waste density and sample localization in the $870 \mathrm{~L}$ waste package are also characterized.

In order to get a discrimination signal from the $238 \mathrm{U} / 235 \mathrm{U}$ isotopes, the ratios of photofission gamma rays with close energies are used so as to eliminate the dependence of attenuation as a function of energy.

\section{Design of the system using numerical simulations}

One of the key issue in photofission examination is related to interfering neutron fission by neutrons produced outside or inside the fissile sample [13]. Tungsten is commonly used as Bremsstrahlung breaking target but it is also a strong photoneutron emitter. Therefore, a new converter has been designed in order to minimize the emission of external photoneutrons impinging the waste package together with the Bremsstrahlung beam. Comparing the Bremsstrahlung yield above the photofission threshold, which is in general around $5 \mathrm{MeV}$ [14], and the photoneutron emission of potential targets by MCNPX calculations, a silicon thick target has been selected. Tables 1 and 2 summarize the main characteristics of possible Bremsstrahlung converters. Photoneutron yields and photofission cross sections are computed for the whole Bremsstrahlung spectrum.

Table 1

Bremsstrahlung yield and integrated uranium photofission cross section in different evaluated Bremsstrahlung converters.

\begin{tabular}{|c|c|c|c|c|c|c|}
\hline & $\begin{array}{l}\text { Target } \\
\text { thickness } \\
(\mathbf{m m})\end{array}$ & $\begin{array}{c}\text { Bremsstrahlung } \\
\text { yield above } \\
5 \mathrm{MeV} \\
\text { (photon per e-) }\end{array}$ & $\begin{array}{l}\text { Photon flux } \\
\text { at } 1 \mathrm{~m}\left(0^{\circ}\right), \\
\text { full energy } \\
\text { range } \\
\left(\mathrm{cm}^{-2} \text { per e-) }\right.\end{array}$ & $\begin{array}{l}\text { Photoneutron } \\
\text { yield at } 1 \mathrm{~m} \\
\text { (cm-2 per e-) }\end{array}$ & $\begin{array}{c}238 U \\
\text { photofission } \\
\text { cross } \\
\text { section } \\
\text { (mb) } \\
\end{array}$ & $\begin{array}{c}235 \mathrm{U} \\
\text { photofission } \\
\text { cross } \\
\text { section } \\
\text { (mb) } \\
\end{array}$ \\
\hline W (15 MeV) & 2.1 & $2.0410^{-1}$ & $6.6610^{-5}$ & $7.6610^{-10}$ & 6.42 & 14.8 \\
\hline $\mathrm{Cu}(12 \mathrm{MeV})$ & 4.7 & $6.0210^{-2}$ & $2.8110^{-5}$ & $2.0610^{-12}$ & 1.94 & 3.77 \\
\hline Mo (12 MeV) & 4.0 & $7.7810^{-2}$ & $2.9810^{-5}$ & $3.4810^{-11}$ & 2.16 & 4.21 \\
\hline $\operatorname{Cr}(12 \mathrm{MeV})$ & 5.9 & $5.1910^{-2}$ & $2.8910^{-5}$ & $2.9410^{-13}$ & 1.85 & 3.58 \\
\hline Si (12 MeV) & 17.1 & $3.9310^{-2}$ & $2.5510^{-5}$ & $2.2810^{-15}$ & 1.63 & 3.13 \\
\hline Si (15 MeV) & 17.1 & $7.0210^{-2}$ & $9.0110^{-5}$ & $1.2410^{-13}$ & 4.24 & 9.64 \\
\hline
\end{tabular}


Table 2

Photonuclear characteristics of Bremsstrahlung target materials. [14]

\begin{tabular}{|c|c|c|c|c|c|}
\hline \multirow[t]{2}{*}{ Target material } & \multicolumn{2}{|c|}{$(\gamma, \mathbf{n})$ cross section (mb) } & \multirow[b]{2}{*}{$15 \mathrm{MeV}$} & \multirow{2}{*}{$\begin{array}{l}\text { Activation } \\
\text { products }\end{array}$} & \multirow[t]{2}{*}{ Half life } \\
\hline & $12 \mathrm{MeV}$ & $13 \mathrm{MeV}$ & & & \\
\hline \multirow{3}{*}{$\mathbf{W}$} & \multirow{3}{*}{300} & \multirow{3}{*}{420} & \multirow{3}{*}{420} & $181 \mathrm{~W}$ & $121.2 \mathrm{~d}$ \\
\hline & & & & $185 \mathrm{~W}$ & $75.1 \mathrm{~d}$ \\
\hline & & & & $185 \mathrm{~mW}$ & $1.6 \mathrm{~min}$ \\
\hline \multirow{2}{*}{$\mathrm{Cu}$} & \multirow{2}{*}{12} & \multirow{2}{*}{20} & \multirow{2}{*}{50} & ${ }^{62} \mathrm{Cu}$ & $9.6 \mathrm{~min}$ \\
\hline & & & & ${ }^{64} \mathrm{Cu}$ & $12.7 \mathrm{~h}$ \\
\hline \multirow{2}{*}{ Mo } & \multirow{2}{*}{$\sim 20$} & \multirow{2}{*}{$\sim 50$} & \multirow{2}{*}{150} & ${ }^{99} \mathrm{Mo}$ & $2.75 \mathrm{~d}$ \\
\hline & & & & ${ }^{91} \mathrm{Mo}$ & $15.49 \mathrm{~min}$ \\
\hline \multirow{2}{*}{$\mathrm{Cr}$} & \multirow{2}{*}{0.5} & \multirow{2}{*}{1} & \multirow{2}{*}{20} & ${ }^{51} \mathrm{Cr}$ & $27 \mathrm{~d}$ \\
\hline & & & & ${ }^{49} \mathrm{Cr}$ & $42.3 \mathrm{~min}$ \\
\hline $\mathbf{S i}$ & 0.05 & 0.05 & 0.07 & - & - \\
\hline
\end{tabular}

2 Despite a lower Bremsstrahlung yield, a $17 \mathrm{~mm}$ thick silicon target produces a superior total 3 photon flux in the forward direction compared to a $2 \mathrm{~mm}$ thick tungsten target (the $\mathrm{Si} / \mathrm{W}$ photon 4 flux ratio is 1.14). On the other hand, the X-ray flux intensity from the silicon converter is 5 decreasing more rapidly at wider angles from the beam centerline (Fig. 1).

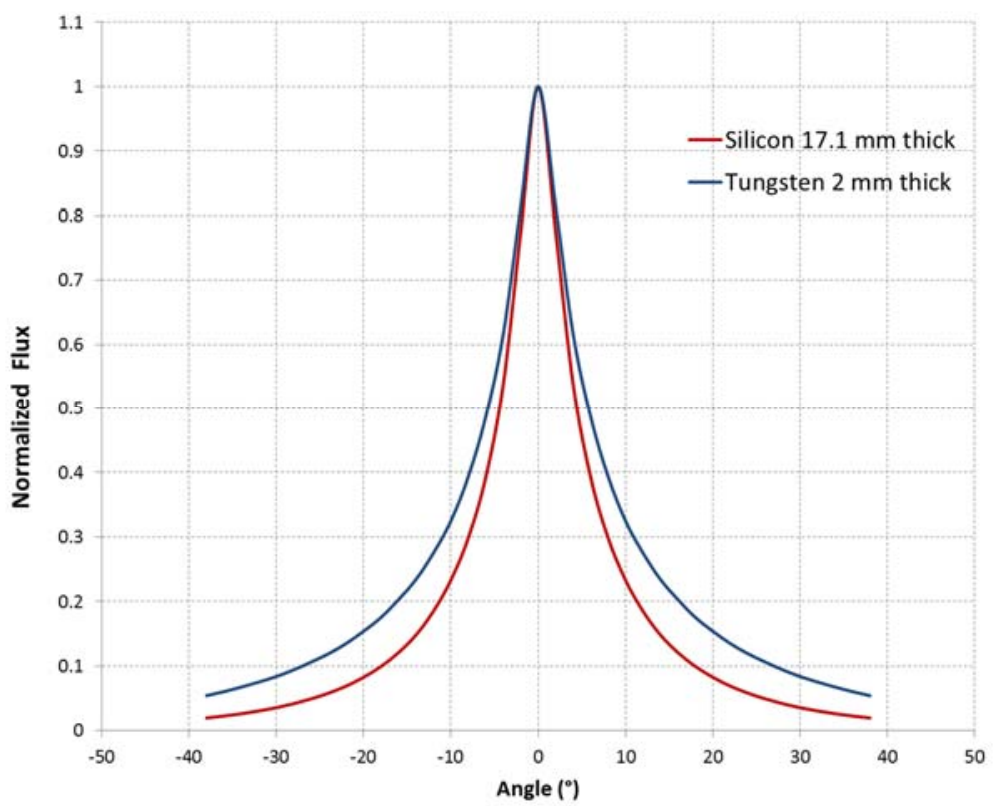

Fig. 1. Bremsstrahlung beam anisotropy from the silicon $17.1 \mathrm{~mm}$ thick target and tungsten $2 \mathrm{~mm}$ thick target above $5 \mathrm{MeV}$ (MCNPX calculations).

The photoneutron production of silicon at $15 \mathrm{MeV}$ is greatly reduced compared to other evaluated target materials. Another benefit of using silicon is the absence of neutron activation.

Figure 2 presents the computed Bremsstrahlung spectra from different converters on the beam axis $\left(0^{\circ}\right)$ and for incident electron energies of $12 \mathrm{MeV}$ and $15 \mathrm{MeV}$. 


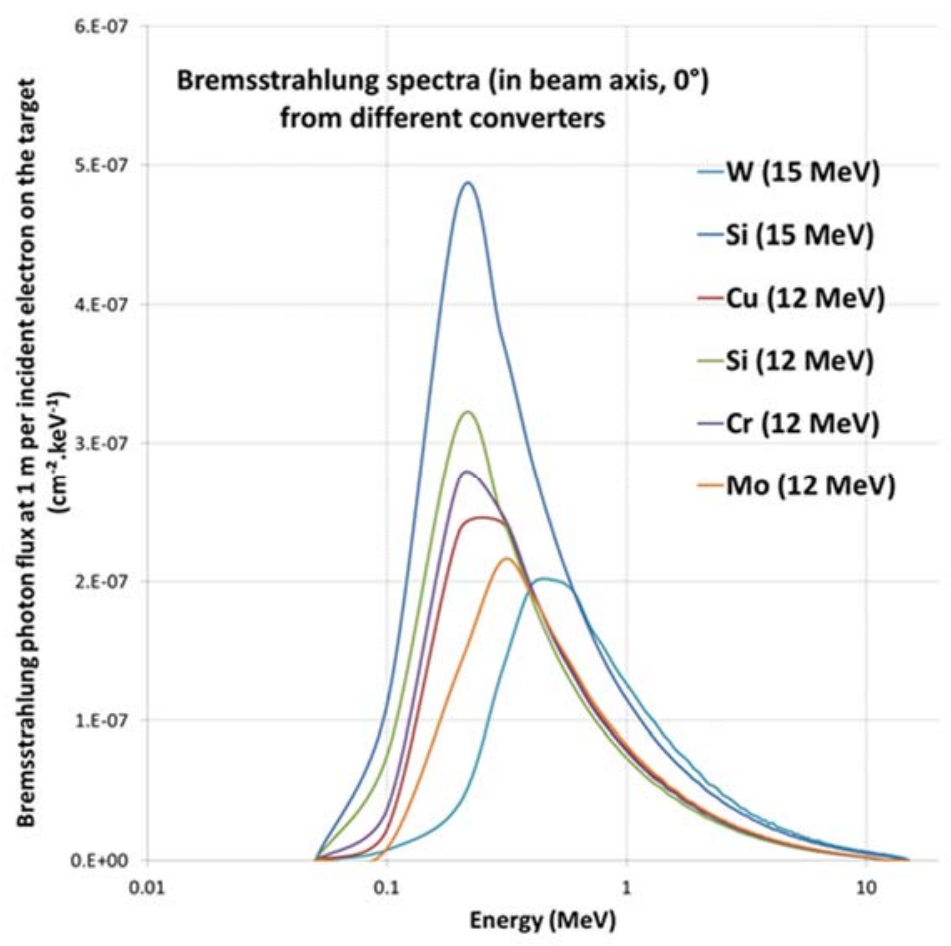

Fig. 2. Bremsstrahlung photon spectra from different converter at $12 \mathrm{MeV}$ or $15 \mathrm{MeV}$ (MCNPX simulations).

The nuclear waste package under investigation is the so called CEA "870L" package [8]. The average uranium content of this package is around $700 \mathrm{~g}$ of ${ }^{238} \mathrm{U}$ and $30 \mathrm{~g}$ of ${ }^{235} \mathrm{U}$.

The 870L model used in these evaluations contains 5 compacted primary waste, surrounded by an hydraulic cement matrix and enclosed in a $3 \mathrm{~mm}$ thick steel container (Fig. 3). The primary waste matrix is considered heterogeneous, containing both metallic and organic materials. The modelled elemental compositions of the waste and hydraulic binder are shown in tables 3 and 4 . The effects related to the location of the uranium sample inside the waste package are evaluated by modelling a penalizing location, i.e. centered in the package, and a more favorable one, in the periphery.

Table 3

Waste matrix elemental composition

\begin{tabular}{cc}
\hline element & \% weight \\
\hline $\mathrm{Fe}$ & 30 \\
$\mathrm{C}$ & 15 \\
$\mathrm{O}$ & 15 \\
$\mathrm{Si}$ & 15 \\
$\mathrm{~N}$ & 5 \\
$\mathrm{H}$ & 5 \\
$\mathrm{Al}$ & 15 \\
\hline
\end{tabular}

13

Table 4

Hydraulic binder elemental composition

\begin{tabular}{cccc}
\hline element & \% weight & element & \% weight \\
\hline $\mathrm{Si}$ & 30.52 & $\mathrm{P}$ & $310^{-2}$ \\
\hline
\end{tabular}




\begin{tabular}{cccc}
\hline $\mathrm{Al}$ & 2.19 & $\mathrm{O}$ & 52.96 \\
$\mathrm{Fe}$ & $9.110^{-1}$ & $\mathrm{~S}$ & $3.7810^{-1}$ \\
$\mathrm{Ca}$ & 9.8 & $\mathrm{Cl}$ & $6.410^{-3}$ \\
$\mathrm{Mg}$ & $4.710^{-1}$ & $\mathrm{Mn}$ & $210^{-2}$ \\
$\mathrm{Na}$ & $710^{-2}$ & $\mathrm{~N}$ & $310^{-5}$ \\
$\mathrm{~K}$ & $8.310^{-1}$ & $\mathrm{H}$ & 1.33 \\
$\mathrm{Ti}$ & $1.110^{-1}$ & & \\
\hline
\end{tabular}

1

In order to maximize the incident Bremsstrahlung flux in the waste package, the Bremsstrahlung target is located 1 meter away from the center of a package. Because of the anisotropic nature of the photon beam (Fig. 1), a rotation of the package is required to perform a homogenous irradiation.

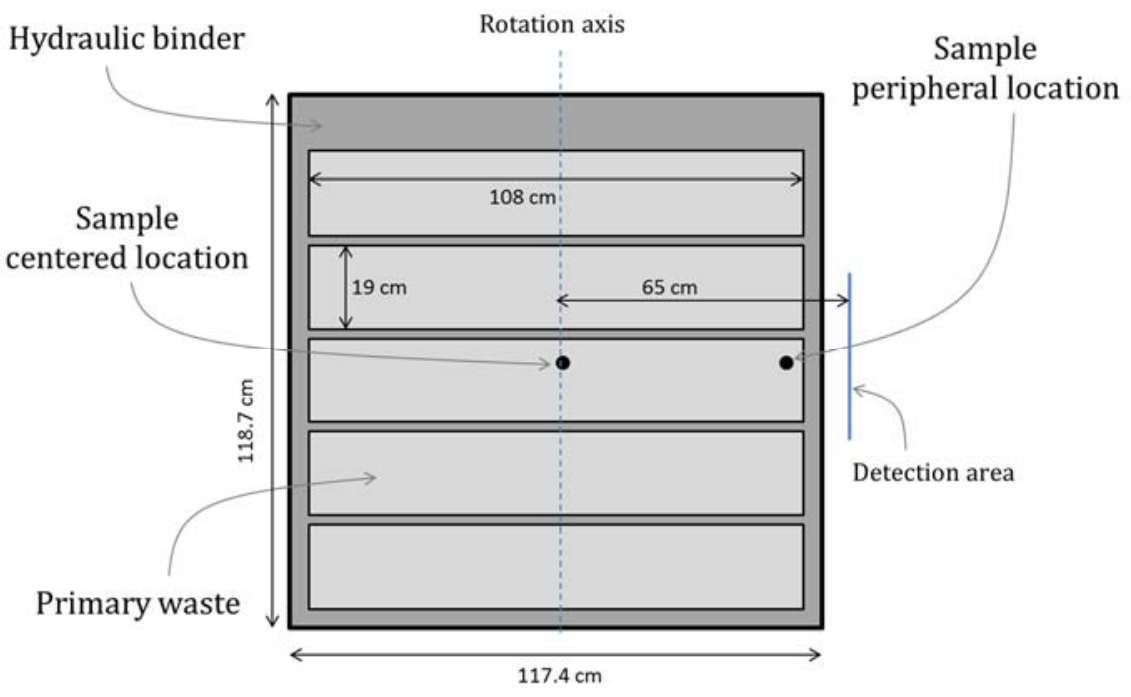

Fig. 3. Geometry of the modelled $870 \mathrm{~L}$ package.

In order to keep the photoneutron background as low as possible, no lead or tungsten collimator is used to angularly sharpen the Bremsstrahlung beam. With this configuration, the flux received by a sample inside the package varies as a function of its distance from the center radius. This X-ray flux modulation is also dependent upon the nature and density of the waste matrix. Figure 4 presents the evolution of the Bremsstrahlung flux between $5 \mathrm{MeV}$ and $15 \mathrm{MeV}$ (which is the useful range for photofission) for samples located at different radii inside the package filled with two kinds of matrix materials. The values are integrated over a $360^{\circ}$ rotation. The effect of sample localization increases with the material density (2.25 vs. $0.69 \mathrm{~g} . \mathrm{cm}^{-3}$ ). 


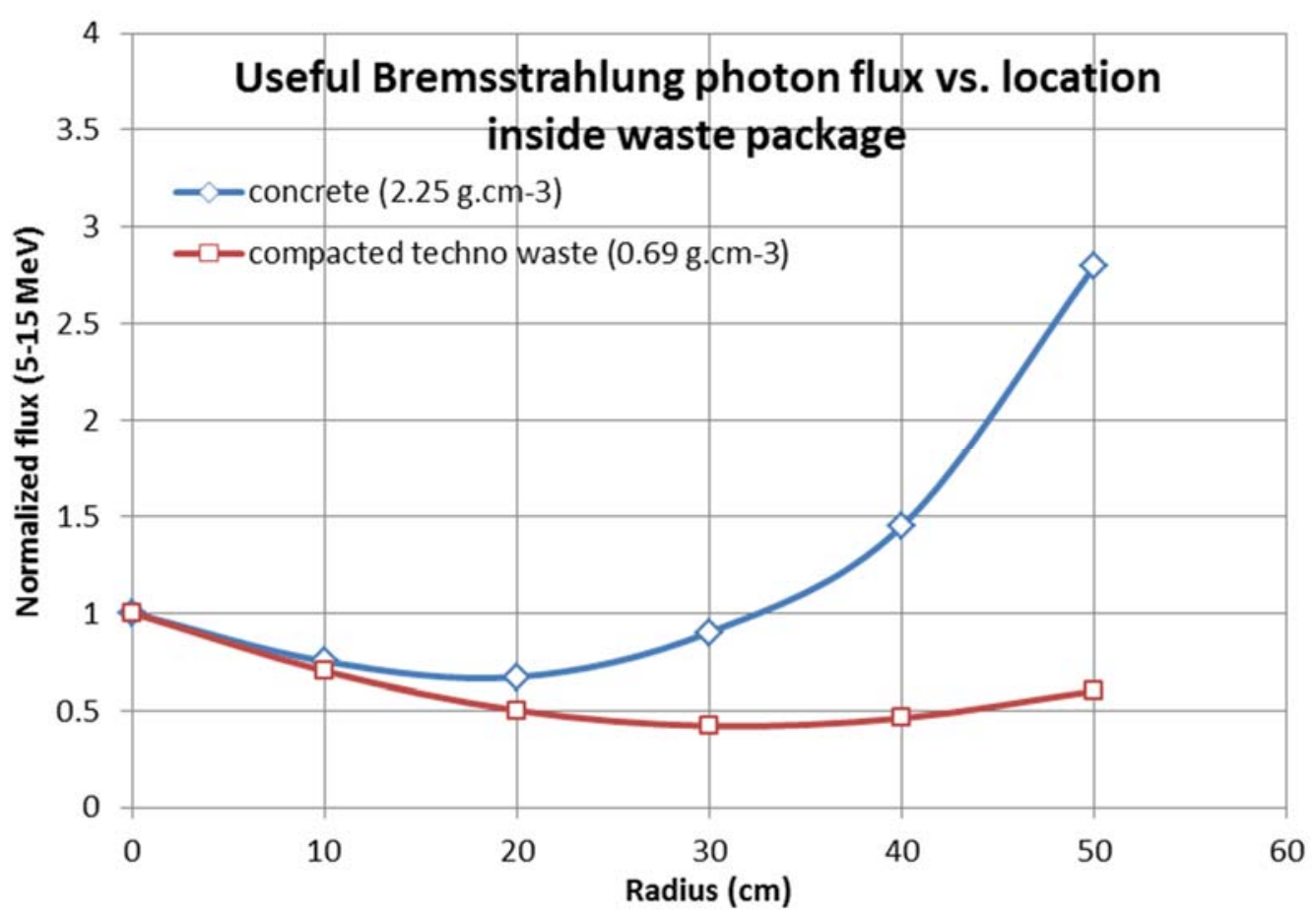

Fig. 4. Integral X-ray flux ( $5 \mathrm{MeV}-15 \mathrm{MeV})$ as a function of the radial location of the uranium sample inside the package. Here the package of Fig. 2 is considered to be fully filled, either by the cement binder or by the waste matrix.

Irradiation is simulated using pulse time characteristics achievable with a standard LINAC: $4.5 \mu \mathrm{s}$ pulses are repeated with a $200 \mathrm{~Hz}$ frequency during 2 hours, and delayed gamma rays are counted after 60 seconds cooling time; the 4 hour post-irradiation gamma-ray spectrum is segmented in 60 min sub-spectra in order to optimize detection limits of the different delayed gamma rays.

The Bremsstrahlung incident beam is produced by impinging $15 \mathrm{MeV}$ electrons in pulsed mode for 2 hours with a current generating a $20 \mathrm{~Gy} / \mathrm{min}$ dose rate at $1 \mathrm{~m}$ in the electron beam direction. The existence of asymmetric geometrical configurations in real waste packages leads to take into account their rotation during examination to reduce localization effects. Instead of multiplying time consuming simulations, the rotation of the waste package is simulated by placing multiple Bremsstrahlung photon sources around the cylindrical waste package.

The delayed gamma-ray production is computed using the ACT FISSION card of MCNPX 2.7.0 and ENDF/BVII photonuclear libraries (Fig.5). Although CPU time when using this feature of MCNPX can become huge, the DG=LINES option (which allows to obtain the delayed gamma-ray lines instead of energy groups) has been selected in order to get the spectral data. One of the main purposes of our photofission based examination is indeed to demonstrate the capability to discriminate between uranium fissile $(235 \mathrm{U})$ and fertile $(238 \mathrm{U})$ isotopes to quantify the fissile mass.

The use of delayed gamma-ray emission for discriminating the isotopic composition of a waste package content has been previously investigated mainly in two ways. The first method is based upon a spectrometric analysis and the computation of specific gamma-ray ratios. The gamma rays are selected to have close energies, and thus having similar attenuation during their transport towards the detector [11][12]. This method using peak ratios could then be rather independent of matrix and sample location heterogeneities. The gamma lines of interest are summarized in table 5 . A second method is based on the measurement of the differential decay time constants of the integral count rate of high energy delayed gamma rays (typically above $3 \mathrm{MeV}$ ) emitted after irradiation. 


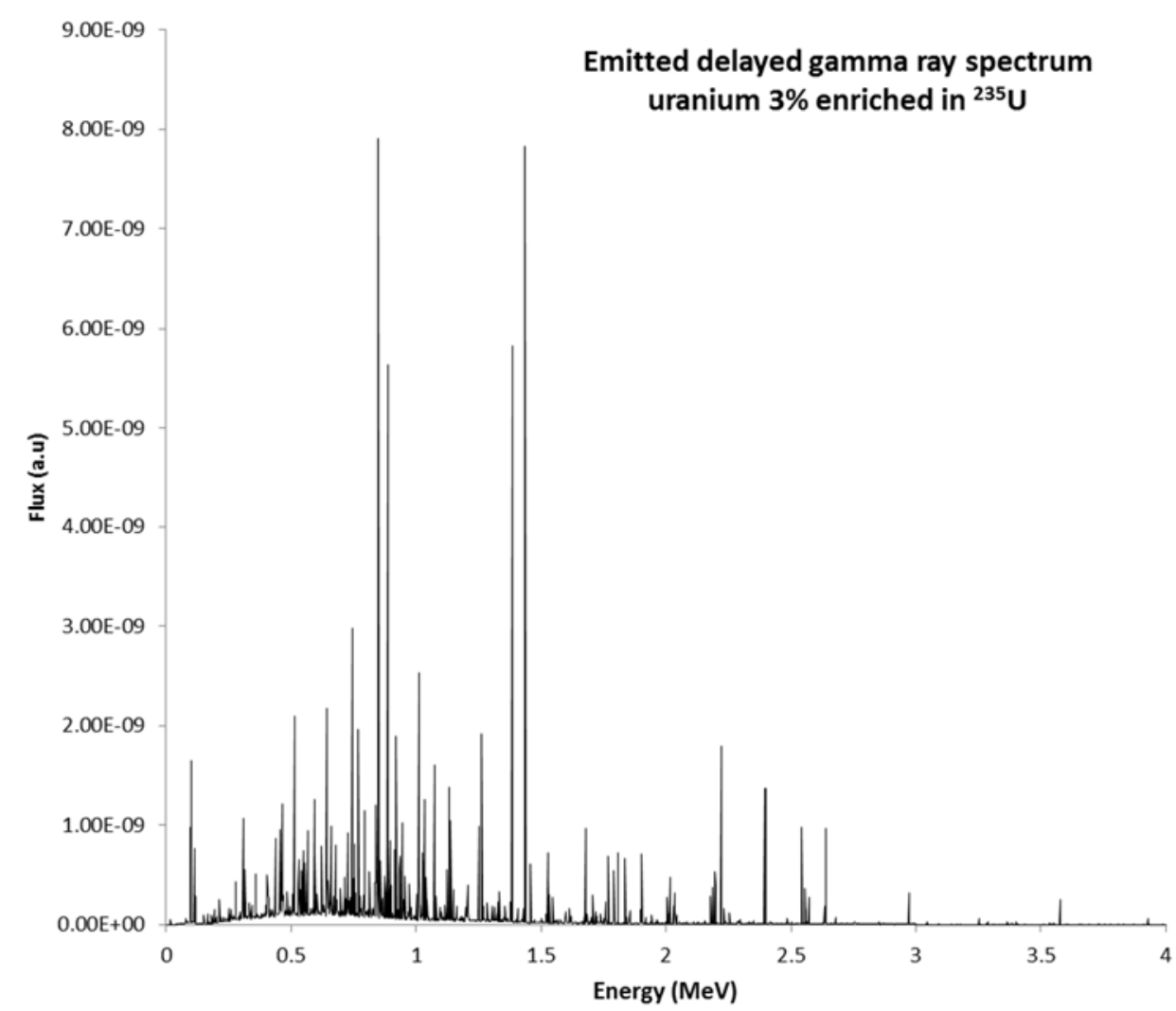

Fig. 5. Emitted photofission delayed gamma-ray spectrum from uranium ( $3 \%$ mass fraction of $235 \mathrm{U}, 97 \%$ of $238 \mathrm{U}$ ) produced with MCNPX ACT FISSION card.

Table 5

Gamma-ray lines of interest from photofission products [5].

\begin{tabular}{ccc}
\hline $\begin{array}{c}\text { Energy } \\
\text { (keV) }\end{array}$ & $\begin{array}{c}\text { Fission } \\
\text { product }\end{array}$ & Half-life \\
\hline $\mathbf{1 3 8 4}$ & ${ }^{92} \mathrm{Sr}$ & $2.61 \mathrm{~h}$ \\
$\mathbf{1 4 3 6}$ & ${ }^{138 \mathrm{Cs}}$ & $33.4 \mathrm{~m}$ \\
\hline $\mathbf{1 7 6 8}$ & ${ }^{138 \mathrm{Xe}}$ & $14.1 \mathrm{~m}$ \\
$\mathbf{1 7 9 1}$ & ${ }^{135 \mathrm{I}}$ & $6.57 \mathrm{~h}$ \\
$\mathbf{1 8 0 6}$ & ${ }^{134 \mathrm{I}}$ & $52.6 \mathrm{~m}$ \\
\hline $\mathbf{2 0 1 6}$ & $138 \mathrm{Xe}$ & $14.1 \mathrm{~m}$ \\
$\mathbf{2 0 3 2}$ & ${ }^{101 \mathrm{Mo}}$ & $14.6 \mathrm{~m}$ \\
\hline $\mathbf{2 1 7 6}$ & ${ }^{95} \mathrm{Y}$ & $10.5 \mathrm{~m}$ \\
$\mathbf{2 1 9 6}$ & ${ }^{89} \mathrm{Rb}$ & $15.32 \mathrm{~m}$ \\
$\mathbf{2 2 1 8}$ & ${ }^{138 \mathrm{Cs}}$ & $32.2 \mathrm{~m}$ \\
\hline $\mathbf{2 3 9 2}$ & ${ }^{88} \mathrm{Kr}$ & $2.82 \mathrm{~h}$ \\
$\mathbf{2 3 9 8}$ & ${ }^{142} \mathrm{La}$ & $1.32 \mathrm{~h}$ \\
\hline
\end{tabular}

7 The only detector able to separate the lines of Tab. 5 is high purity germanium (HPGe). In order to

8 be used in a photofission system with a high flux of photoneutrons, it has to be radiation hardened

9 (N type HPGe crystal). In addition, it must have good detection efficiency for gamma rays above 1

$10 \mathrm{MeV}$. A multiple detector system comprising five HPGe detectors (45\% efficiency) with a $2 \mathrm{keV}$ resolution at $1332 \mathrm{keV}$ has been considered. The detector cluster is intended to be protected from scattered photons, photoneutrons and prompt fission and photofission neutrons by a dedicated shielding wall during the irradiation phase. At the end of irradiation, the detector cluster will be moved to its measurement location near the waste package. The distance taken into account 
between the detectors entrance window and the package axis is $65 \mathrm{~cm}$ (i.e. around $15 \mathrm{~cm}$ from its wall).

\section{Signal and background calculations}

The number of photofission reactions has been calculated as a function of the mass of an uranium sample enriched at $20 \%$ in $235 \mathrm{U}$ from $1 \mathrm{~g}$ up to $1000 \mathrm{~g}$, and for two different sample locations (centered and peripheral). The photofission rate follows a non-linear evolution as a function of the sample mass, due to self-shielding of incident interrogating photons (Fig. 6 and 7). This nonlinearity is less pronounced in the central location due to the hardening of the incident X-ray beam reaching the sample. Fig. 8 shows the spectrum shape computed by MCNPX at the two sample locations within the package (peripheral and centered), showing the differential attenuation (beam hardening). In the linear range region of Fig. 6 and 7 (low uranium masses), the photofission rate sensitivity is $1.6510^{5} \mathrm{~s}^{-1} . \mathrm{g}^{-1}$ with the centered sample and $2.7210^{5} \mathrm{~s}^{-1} \cdot \mathrm{g}^{-1}$ in peripheral location. The difference is small compared to other techniques such as neutron interrogation, for which the signal would be reduced by more than a decade between the outer and center positions, because of the high absorption of thermal interrogating neutrons by hydrogen nuclei. Indeed, thermal neutron interrogation is highly sensitive to any absorbing elements that might be present in the waste matrix, such as hydrogen, boron, chlorine, cadmium, etc.

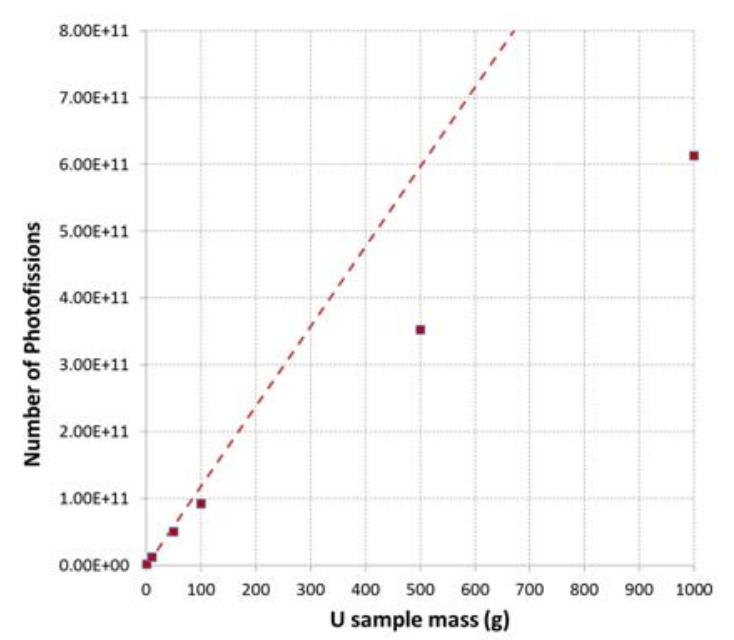

Fig. 6. Number of photofissions induced in the $20 \%$ enriched uranium sample in centered location inside $870 \mathrm{~L}$ waste package, after $2 \mathrm{~h}$ irradiation.

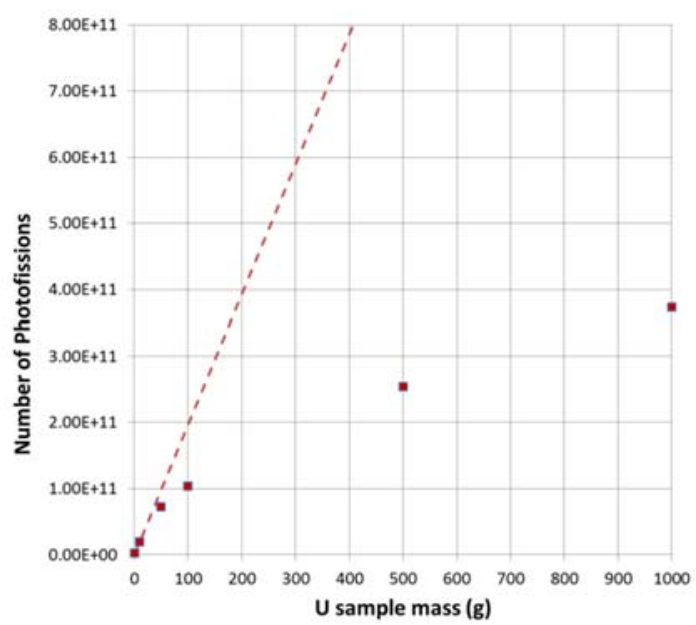

Fig. 7. Number of photofissions induced in the $20 \%$ enriched uranium sample in peripheral location inside $870 \mathrm{~L}$ waste package, after $2 \mathrm{~h}$ irradiation. 


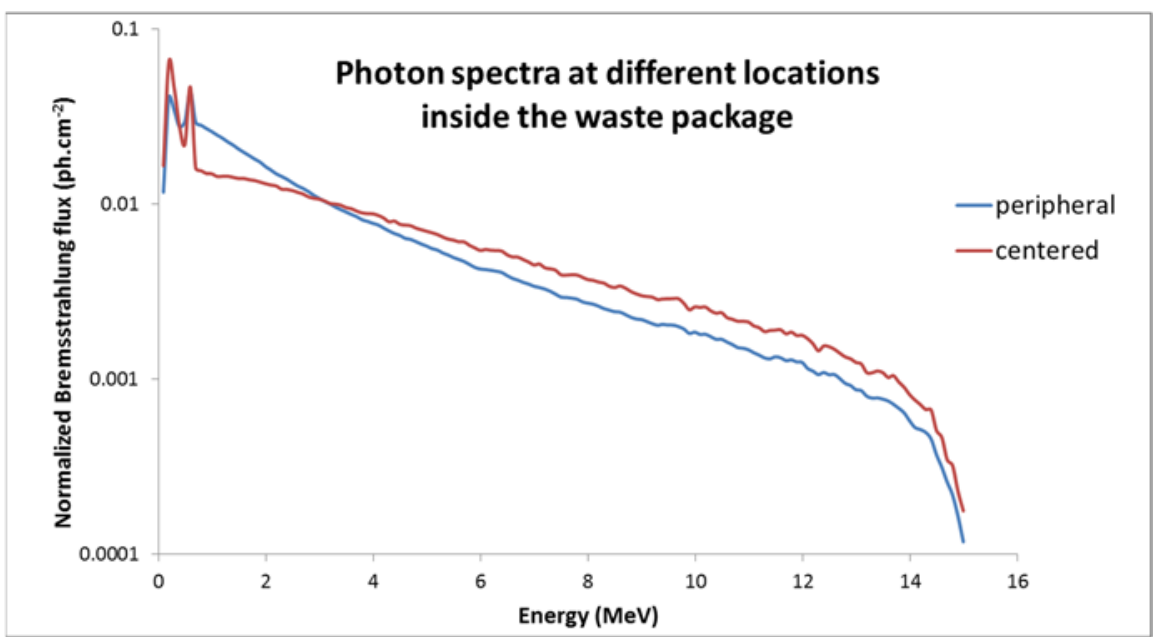

Fig. 8 : Spectrum hardening between peripheral and centered locations within the waste package. Low energy events visible in both spectra are annihilation and Compton scattering photons from beam interactions.

The main source of parasitic fission signal in photofission examination is due to either external photoneutrons or to neutrons produced in the sample itself (photoneutrons or prompt fission neutrons produced in uranium). Their impact on the total fission signal has been evaluated by computing the neutron flux arriving at the surface of the uranium sample, with and without uranium in the model, and by convoluting these fluxes with the neutron fission cross section (using the MCNPX tally multiplier card). The obtained fission rates have then been compared to the total (mainly photo-) fission rate. Table 6 summarizes the evaluation of these spurious neutron fission events in the two geometrical sample configurations.

The spurious neutron fissions produced by external neutrons, mainly coming from interactions of the X-ray beam with the package, only represents less than $0.2 \%$ of the total fissions. The origin of the external neutrons has been estimated by modifying some elements of geometry (calculations of the neutron flux inside package with or without the uranium sample), showing that a proportion (around 1\%) comes from the silicon target, most of the photoneutrons being produced within the package before reaching the center of the matrix.

On the other hand, fissions due to neutrons produced inside uranium are more numerous (up to $17 \%$ for the $500 \mathrm{~g}$ sample in the periphery). Nevertheless, they will not lead to an excessive overestimation of the uranium mass measured by photofission.

\section{Table 6}

Proportion of parasitic neutron fissions with respect to total (mainly photo-) fissions, as a function of sample mass (20\% enriched uranium).

\begin{tabular}{llccc}
\hline & & $\mathbf{1 0} \mathbf{g}$ & $\mathbf{1 0 0 g}$ & $\mathbf{5 0 0 g}$ \\
\hline \multirow{2}{*}{$\begin{array}{l}\text { Centered } \\
\text { location }\end{array}$} & Fissions from external neutrons & $0.08 \%$ & $0.14 \%$ & $0.16 \%$ \\
& Fissions from sample neutrons & $1.42 \%$ & $5.90 \%$ & $1.32 \%$ \\
& Total & $1.53 \%$ & $6.04 \%$ & $10.48 \%$ \\
\hline \multirow{2}{*}{$\begin{array}{l}\text { Peripheral } \\
\text { location }\end{array}$} & Fissions from external neutrons & $0.03 \%$ & $0.09 \%$ & $0.14 \%$ \\
& Fissions from sample neutrons & $4.47 \%$ & $9.34 \%$ & $16.74 \%$ \\
& Total & $4.50 \%$ & $9.43 \%$ & $16.88 \%$ \\
\hline
\end{tabular}


The useful photofission signal is computed from the photofission rate calculated above and from the ACT fission card. The time dependence of the delayed gamma-ray emission is computed by segmenting with a time card the outgoing gamma-ray flux with a F4 tally. Then the pulse height spectrum (F8 tally) in the HPGe detector corresponding to the different time windows is calculated by considering a normal photon incidence on the detector entrance window (Fig. 9). The total count rate due to photofission events is low (134 counts. $\mathrm{s}^{-1}$ in the configuration of Fig. 3 ).

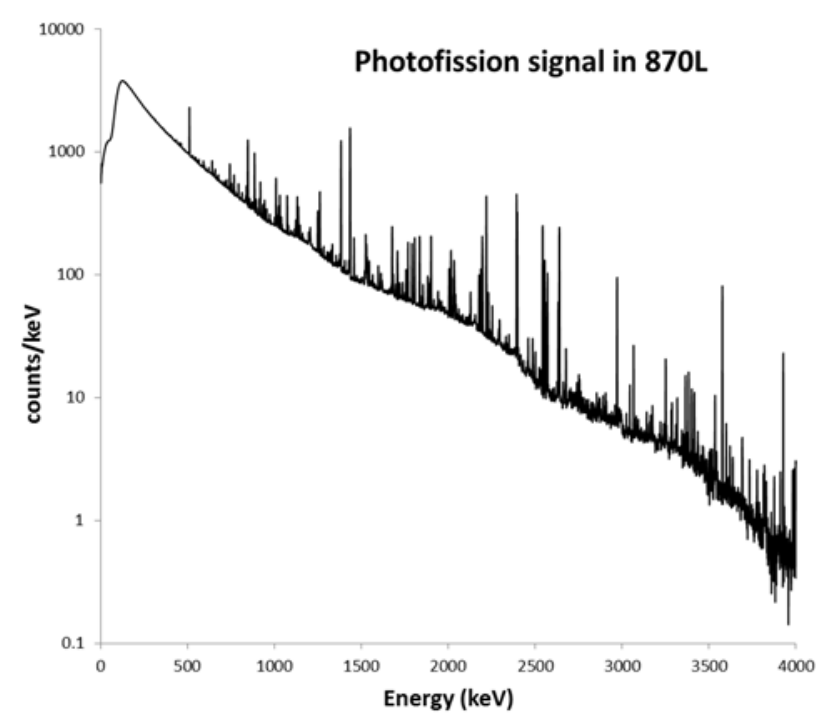

Fig. 9. Photofission signal spectrum of the $870 \mathrm{~L}$ package ( $2 \mathrm{~h}$ irradiation, $3 \mathrm{~h}$ counting).

The passive gamma background of the 870L package has been evaluated by modelling the average gamma emission of the main isotopes.

The gamma-ray source is considered homogeneously distributed in the volume of the primary compacted waste inside the 870L package. The simulated source includes 6 isotopes representing the essential of the gamma emission of the 870L waste package. Fig. 10 shows the passive background spectrum computed for 3 h counting in a $45 \%$ relative efficiency germanium detector located at $65 \mathrm{~cm}$ away from the package axis.

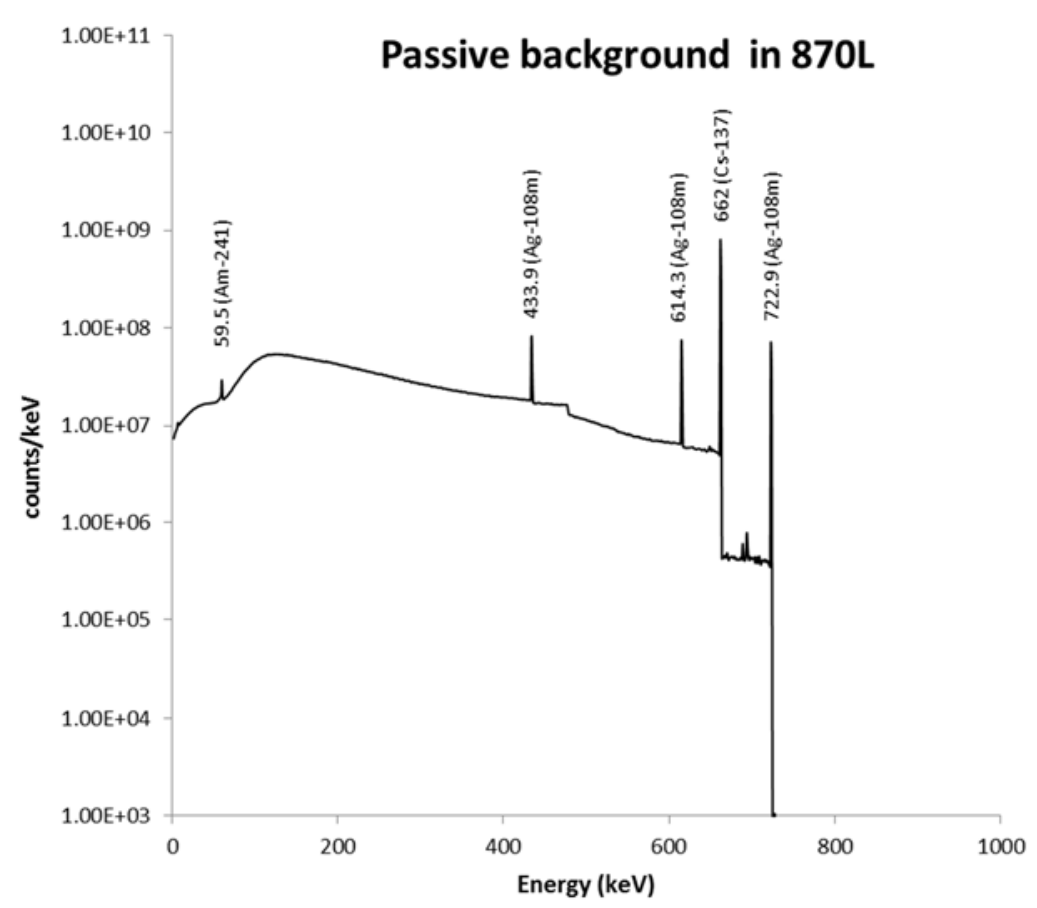

Fig. 10. Passive background spectrum of the $870 \mathrm{~L}$ package ( $3 \mathrm{~h}$ counting). 
The count rate is very large, around $1.510^{6}$ counts.s $^{-1}$, but the passive gamma background is entirely below $1 \mathrm{MeV}$, dominated by the $662 \mathrm{keV}$ line of ${ }^{137} \mathrm{Cs}$. The acquisition electronics should be carefully optimized in order to not disturb the high energy part of the spectrum by pulse pile-up effects (the delayed gamma rays of interest shown in further Table 8 are above $1.3 \mathrm{MeV}$ ).

In order to reduce the passive background, a detector collimation could be used, in particular when the uranium sample has been previously localized (by transmission imaging or photofission tomography as discussed in the conclusion).

On the other hand, the detection of photofission delayed gamma rays might be perturbed by the delayed gamma emission of nonnuclear materials activated during the irradiation phase. This active background is mainly composed of isotopes produced by neutron and photonuclear activation. To quantify this active background, the calculation is performed in several steps. First, the rates of all reactions of interest are computed using MCNPX in the cement binder and in the compacted waste separately. Then, the activity of background isotopes is calculated during the counting period of photofission delayed gamma rays. Finally, active background gamma-ray spectra are computed using the MCNPX pulse height tally in the detector. The considered activation reactions considered are: $(\gamma, n),(\gamma, p),(n, p),(n, 2 n),(n, \alpha),(n, \gamma)$. More than 40 isotopes are taken into account for this evaluation.

The activation of the package is dominated by ${ }^{13} \mathrm{~N}$ (half-life $9.96 \mathrm{~min}$ ), ${ }^{11} \mathrm{C}$ (half-life $20.33 \mathrm{~min}$ ), and 150 (half-life $122 \mathrm{~s}$ ). These $\beta^{+}$emitters indeed lead to an intense $511 \mathrm{keV}$ annihilation line (Fig. 11). The total count rate of the active background is $1.810^{4}$ counts.s $\mathrm{s}^{-1}$, which is two orders of magnitude lower than passive background. However, many gamma lines are present in the useful area of the spectrum between $1.3 \mathrm{MeV}$ and $3 \mathrm{MeV}$.

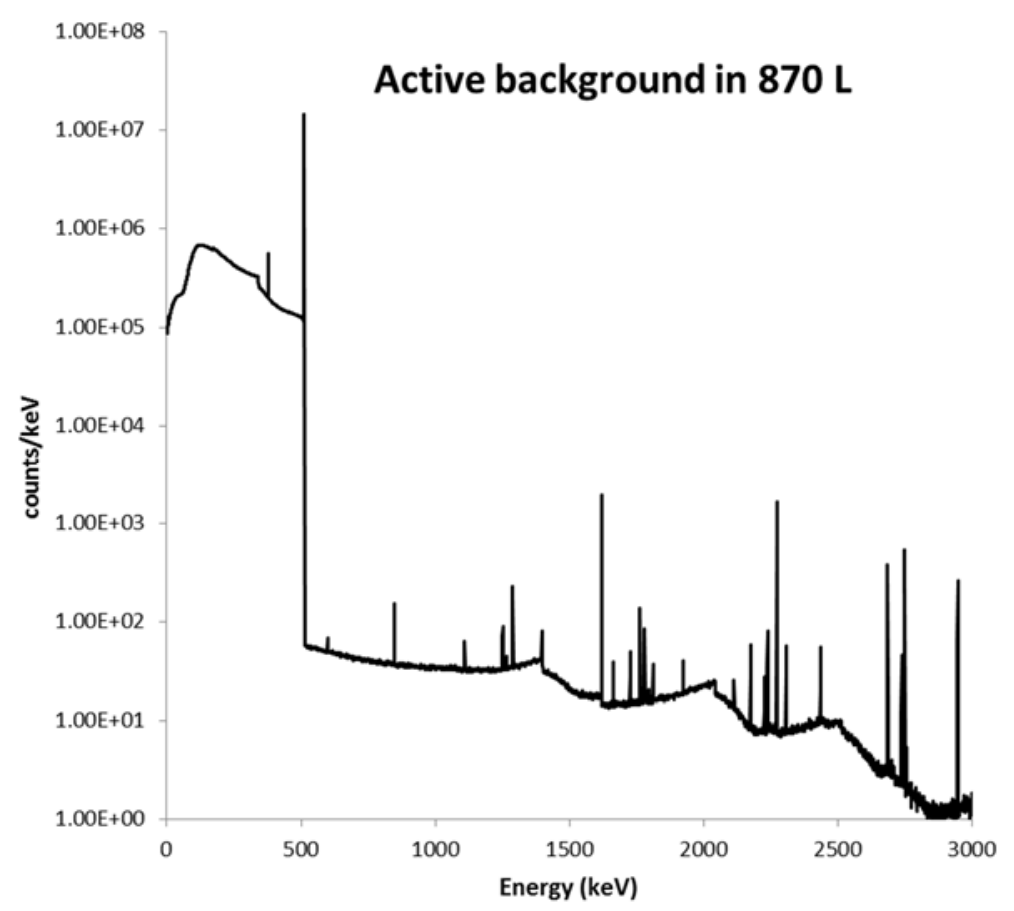

Fig. 11. Active background spectrum of the $870 \mathrm{~L}$ package ( $2 \mathrm{~h}$ irradiation, $3 \mathrm{~h}$ counting).

The gamma lines of the active background responsible of the Compton continuum present in the useful area of the spectrum are detailed in Table 7. The single escape line of $2686 \mathrm{keV}$ gamma ray ( ${ }^{53} \mathrm{Fe}$ ) at $2175 \mathrm{keV}$ interferes with the $2176 \mathrm{keV}$ delayed photofission gamma ray (see Tab. 8). The subtraction of the $2686 \mathrm{keV}$ single escape line (SE) should however be possible thanks to the 2686 keV full-energy line and the associated double escape line (DE) at $1664 \mathrm{keV}$, knowing the HPGe detector respective efficiencies of the 3 peaks by MCNPX simulations. 
Gamma ray lines present in the useful area of the spectrum.

\begin{tabular}{|c|c|c|c|}
\hline $\begin{array}{c}\text { Line } \\
(\mathrm{keV})\end{array}$ & Origin & $\begin{array}{c}\text { Line } \\
\text { (keV) }\end{array}$ & Origin \\
\hline 1397 & ${ }^{53} \mathrm{Fe}$ & 2238 & SE from $2749 \mathrm{keV}$ \\
\hline 1620 & ${ }^{53} \mathrm{Fe}$ & 2274 & ${ }^{53} \mathrm{Fe}$ \\
\hline 1664 & DE from $2686 \mathrm{keV}$ & 2308 & ${ }^{53} \mathrm{Fe}$ \\
\hline 1727 & DE from $2749 \mathrm{keV}$ & 2436 & SE from $2947 \mathrm{keV}$ \\
\hline 1763 & SE from $2274 \mathrm{keV}$ & 2523 & $56 \mathrm{Mn}$ \\
\hline 1779 & ${ }^{28} \mathrm{Al}$ & 2686 & ${ }^{53} \mathrm{Fe}$ \\
\hline 1797 & SE from $2308 \mathrm{keV}$ & 2738 & SE from $3249 \mathrm{keV}$ \\
\hline 1811 & ${ }^{56} \mathrm{Mn}$ & 2749 & ${ }^{53} \mathrm{Fe}$ \\
\hline 1925 & DE from de $2947 \mathrm{keV}$ & 2754 & ${ }^{24} \mathrm{Na}$ \\
\hline 2113 & ${ }^{56} \mathrm{Mn}$ & 2947 & ${ }^{53} \mathrm{Fe}$ \\
\hline 2175 & SE from $2686 \mathrm{keV}$ & 2960 & $56 \mathrm{Mn}$ \\
\hline 2227 & DE from $3249 \mathrm{keV}$ & & \\
\hline
\end{tabular}

3

\section{4. Detection limits and spectroscopy of delayed gamma rays}

5 The mass detection limit is computed for each of the 12 photofission delayed gamma-ray lines of 6 interest from the useful signal S (counts in the net area per uranium mass unit) and background B 7 (counts in the area of interest for both the passive and the active backgrounds), for 2 hour 8 irradiation and $3 \mathrm{~h}$ counting times, using eq.(1) [15] :

$$
\left.\operatorname{LD}(\mathrm{g})=\frac{2.71+3.29 \sqrt{B\left(1+\frac{n}{2 m}\right)}}{S} \quad \text { (eq. } 1\right)
$$

where $\mathrm{n}$ is the number of bins in the peak, and $\mathrm{m}$ is the number of bins used to compute the background on both sides of the peaks.

The mass detection limit for each line of interest is given in table 8 .

Table 8

Detection limit for the 12 lines of interest

\begin{tabular}{cccc}
\hline Line (keV) & $\mathbf{L}_{\mathbf{D}}$ (counts) & \multicolumn{2}{c}{$\mathbf{L}_{\mathbf{D}}$ (g) } \\
\hline & & centered & peripheral \\
\hline 1384 & 75 & 0.31 & 0.022 \\
1436 & 115 & 0.36 & 0.026 \\
1768 & 86 & 3.43 & 0.264 \\
1791 & 86 & 3.43 & 0.291 \\
1807 & 83 & 2.78 & 0.240 \\
2016 & 105 & 4.18 & 0.42 \\
2032 & 107 & 3.56 & 0.497 \\
2176 & 63 & 4.22 & 0.434 \\
2196 & 61 & 1.22 & 0.117 \\
2218 & 63 & 0.74 & 0.071 \\
2392 & 65 & 0.72 & 0.022 \\
2398 & 65 & 1.00 & 0.026 \\
\hline
\end{tabular}


Figure 12 shows the evolution of the mass detection limit obtained for each line of interest as a function of the waste density. The mass detection limit increases rapidly when the waste density increases from 0.5 to 2.5 . In this density range, the mass detection limit drops by a factor of around 3 decades. Despite this strong evolution which highlights the necessity to measure the waste density (for instance by photon tomodensitometry with the same LINAC), all lines of interest exhibit a detection limit lower than the expected average uranium mass content in the package $(\sim 750 \mathrm{~g})$ up to a waste density of 2.0 , and for 6 lines up to a density of 2.5 .

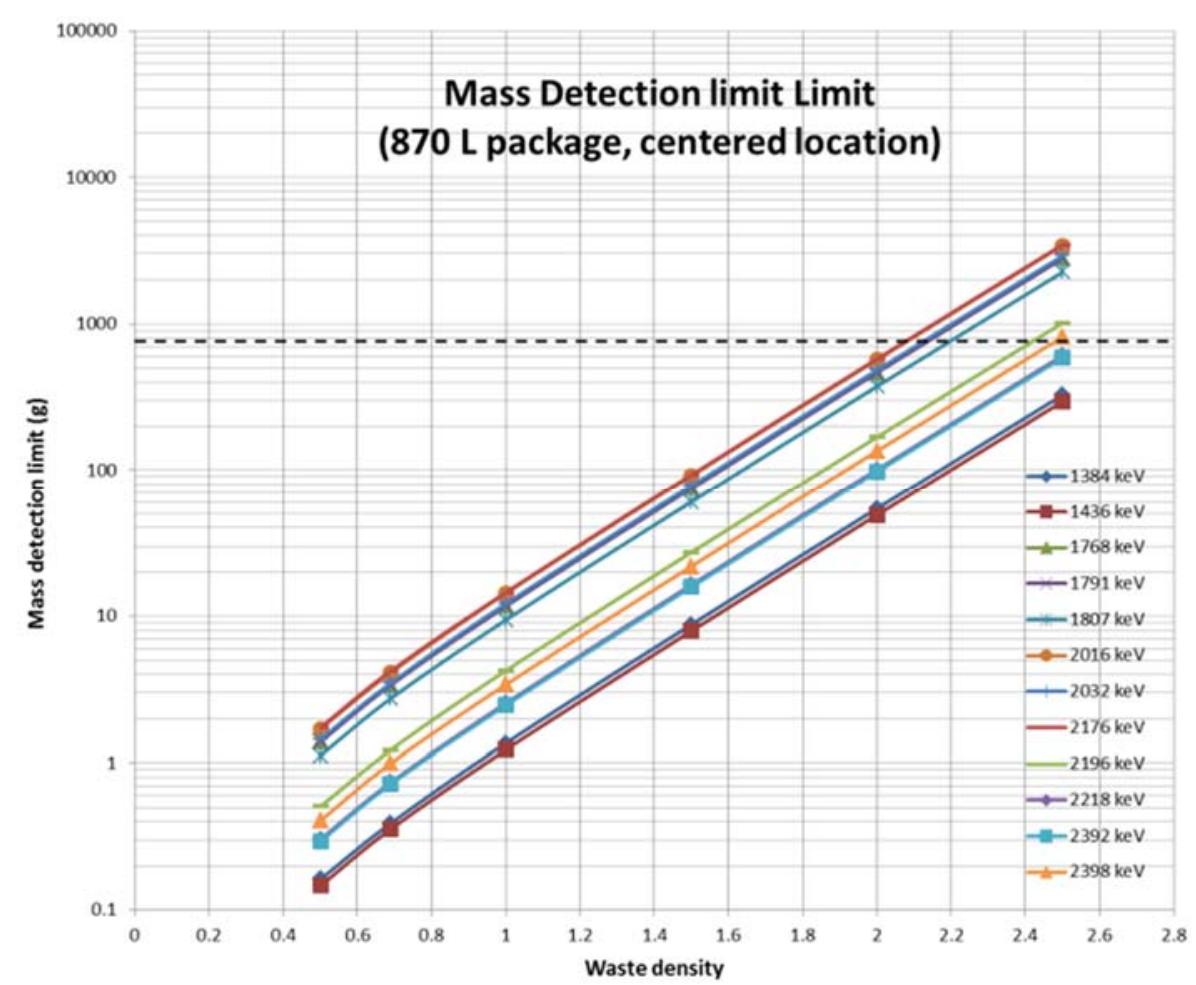

Fig. 12. Uranium detection limits of the photofission delayed gamma rays of interest ( $2 \mathrm{~h}$ irradiation, $3 \mathrm{~h}$ counting), for a sample in the center of the $870 \mathrm{~L}$ package. The average uranium mass content of the package is figured by the horizontal dashed line.

Seven delayed gamma peak ratios have been calculated as a function of uranium enrichment in view to test the feasibility of ${ }^{235} \mathrm{U}$ vs. ${ }^{238} \mathrm{U}$ discrimination. These ratios have been evaluated with the 12 above lines of interest for two sample locations, centered and peripheral, as reported in tables 9 and 10, respectively. The ratios are remarkably similar from one sample location to the other.

\section{Table 9}

Peak ratios computed for a centered $100 \mathrm{~g}$ sample, from pure ${ }^{238} \mathrm{U}$ to $25 \%$ enriched uranium.

\begin{tabular}{cccccccc}
\hline & \multicolumn{7}{c}{ Uranium-235 enrichment (\%) } \\
\hline Peak ratio & $\mathbf{0}$ & $\mathbf{3}$ & $\mathbf{5}$ & $\mathbf{1 0}$ & $\mathbf{1 5}$ & $\mathbf{2 0}$ & $\mathbf{2 5}$ \\
\hline $1384 / 1436$ & 0.623 & 0.630 & 0.644 & 0.646 & 0.669 & 0.672 & 0.684 \\
$1768 / 1791$ & 1.290 & 1.224 & 1.216 & 1.159 & 1.054 & 1.026 & 1.007 \\
$1791 / 1807$ & 0.733 & 0.745 & 0.743 & 0.760 & 0.823 & 0.854 & 0.856 \\
$2016 / 2032$ & 0.806 & 0.816 & 0.798 & 0.815 & 0.801 & 0.807 & 0.774 \\
$2176 / 2196$ & 0.314 & 0.307 & 0.308 & 0.301 & 0.267 & 0.279 & 0.291 \\
$2196 / 2218$ & 0.481 & 0.505 & 0.514 & 0.550 & 0.593 & 0.589 & 0.599
\end{tabular}


Peak ratios computed for a peripheral 100 g sample, from pure U-238 to $25 \%$ enriched uranium.

\begin{tabular}{cccccccc}
\hline & \multicolumn{7}{c}{ Uranium-235 enrichment (\%) } \\
\hline Peak ratio & $\mathbf{0}$ & $\mathbf{3}$ & $\mathbf{5}$ & $\mathbf{1 0}$ & $\mathbf{1 5}$ & $\mathbf{2 0}$ & $\mathbf{2 5}$ \\
\hline $1384 / 1436$ & 0.644 & 0.652 & 0.666 & 0.668 & 0.693 & 0.694 & 0.707 \\
$1768 / 1791$ & 1.309 & 1.279 & 1.262 & 1.184 & 1.087 & 1.048 & 1.038 \\
$1791 / 1807$ & 0.737 & 0.742 & 0.740 & 0.757 & 0.816 & 0.850 & 0.858 \\
$2016 / 2032$ & 0.831 & 0.841 & 0.833 & 0.855 & 0.833 & 0.833 & 0.810 \\
$2176 / 2196$ & 0.324 & 0.315 & 0.315 & 0.304 & 0.272 & 0.283 & 0.296 \\
$2196 / 2218$ & 0.480 & 0.505 & 0.511 & 0.550 & 0.590 & 0.589 & 0.601 \\
$2392 / 2398$ & 0.923 & 0.990 & 0.999 & 1.129 & 1.236 & 1.404 & 1.447 \\
\hline
\end{tabular}

Among the seven evaluated ratios, the $1768 \mathrm{keV} / 1791 \mathrm{keV}$ and $2392 \mathrm{keV} / 2398 \mathrm{keV}$ ones show respectively $20.7 \%$ and $56.8 \%$ variation between $0 \%$ and $25 \%$ enrichment of $235 \mathrm{U}$, which is a priori a sufficient contrast to estimate the uranium enrichment (Fig. 13).

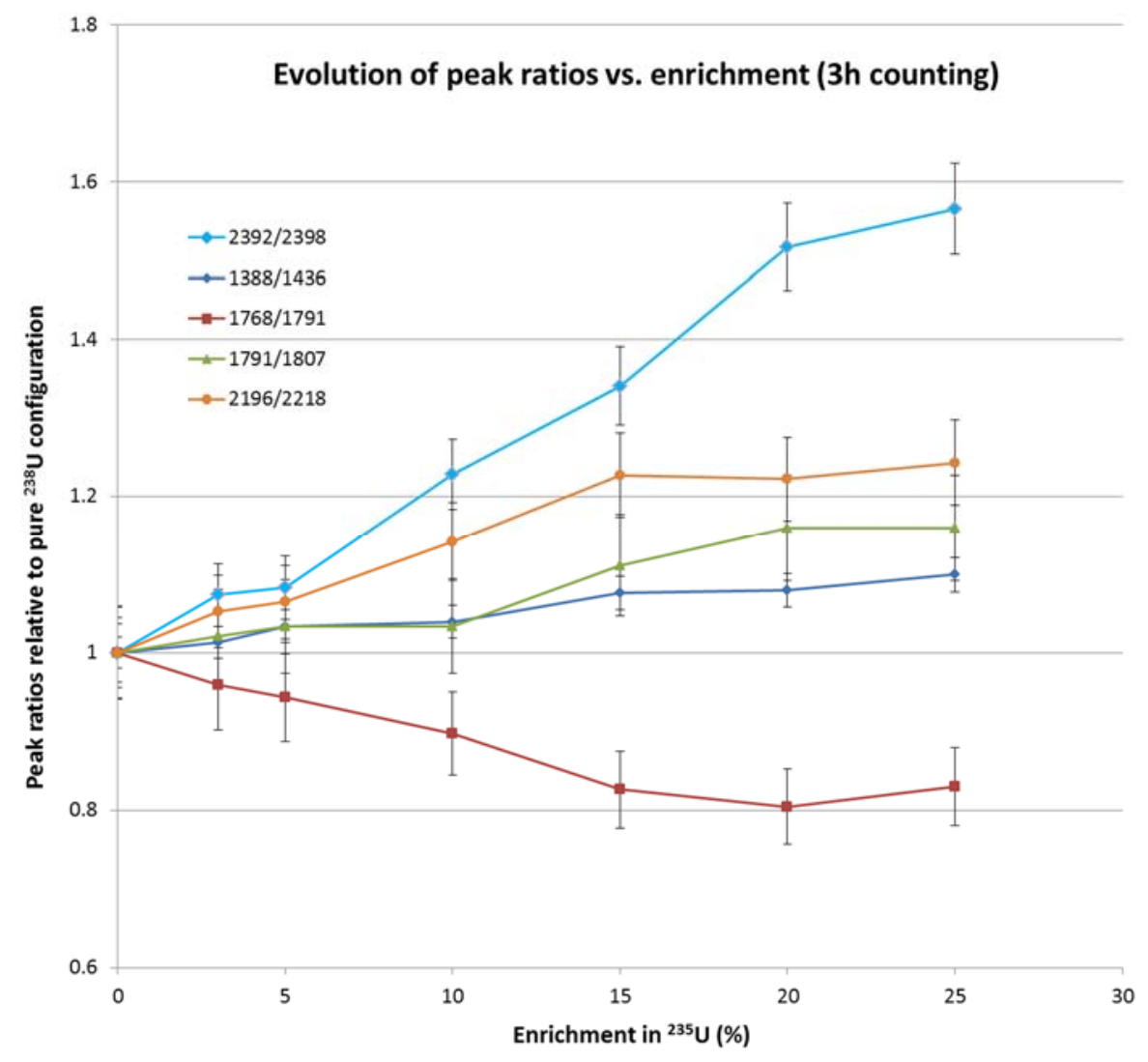

Fig. 13. Peak ratios as a function of uranium enrichment.

\section{Discussion and conclusion}

A non-destructive examination system of a 870L nuclear waste package based on the detection of photofission delayed gamma rays has been assessed with MCNPX calculations. The envisaged setup involving a $15 \mathrm{MeV}$ Linac Bremsstrahlung beam and a cluster of 5 HPGe detectors would be a priori sufficient to measure the fissile mass through a spectroscopic analysis of photofission delayed gamma rays. 
The achievable detection limits of the delayed gamma rays of interest are lower than the average uranium mass $(\sim 750 \mathrm{~g})$ in the waste package, even for a wide range of waste densities and sample localizations. However, these two parameters have a high impact on measurement sensitivity. This expected behavior indicates the necessity to accurately assess both the localization of uranium and the density of the waste in order to precisely quantify uranium (total or fissile mass). This additional information could be supplied in two ways. First by implementing high energy photon tomo-densitometry [16][17][18], with the same Bremsstrahlung beam but specific imaging detectors. Second, by using photofission emission tomography [19][20], either with delayed neutrons or gamma rays.

The high gamma-ray background encountered with in this kind of detectors close to the $870 \mathrm{~L}$ irradiant package is also of concern. Even if the useful photofission signal is free from direct interferences with gamma rays from the package emitted at lower energy, the high count-rate should be taken into account to limit saturation and pulse pile-up effects, which could significantly impair the detection capability of photofission delayed gamma rays. A detector collimation could be envisaged for this purpose, leading to the examination of a restricted area in the waste package.

On the other hand, in order to estimate the fissile mass in nuclear waste packages, plutonium must be measured along with uranium. The feasibility of its quantification using delayed gamma rays from photofission is the next step to address. In this view, nuclear data regarding delayed gamma rays from photofission of plutonium isotopes will be evaluated by computational means. The plutonium mass in the waste packages is generally much lower than the uranium mass, but the fraction of fissile isotopes $\left({ }^{239} \mathrm{Pu},{ }^{241} \mathrm{Pu}\right)$ is larger. Finally, mixed uranium and plutonium samples will be studied, first numerically and then experimentally.

The encouraging results obtained for uranium photofission delayed gamma rays in the 870L package pave the way to examinations of other types of dense, hydrogenous, and heterogeneous waste packages whose fissile mass cannot be accurately quantified by neutron-based active interrogation.

\section{Acknowledgement}

This work is supported by the French National Radioactive Waste Management Agency (Andra) under the CHK contract in the field of nuclear waste management.

\section{References}

[1] F. Jallu, A. Lyoussi, C. Passard, E. Payan, H. Recroix, G. Nurdin, A. Buisson, J. Allano

The simultaneous photon and neutron interrogation method for fissile and non-fissile element separation in radioactive waste drums

Nucl. Instr. Meth. B, 170 (2000), p. 489

[2] A-C. Raoux, A. Lyoussi, C. Passard, C. Denis, J. Loridon, J. Misraki, P. Chany

Transuranic waste assay by neutron interrogation and online prompt and delayed neutron measurement,

Nucl. Instr. Meth. B, 207(2003), p. 186

[3] F. Jallu, , C. Passard, E. Brackx

Application of active and passive neutron nondestructive assay methods to concrete radioactive waste drums

Nucl. Instr. Meth. B, 170 (2000), p. 489

[4] B. Pérot, Jean-Luc Artaud, Christian Passard, Anne-Cécile Raoux

Experimental qualification with a scale one mock-up of the measurement and sorting unit" for bituminized waste drums 
Proceedings of ICEM '03: The 9th International Conference on Radioactive Waste Management and Environmental Remediation, September 21 - 25, 2003, Examination School, Oxford, England

[5] F. Carrel, M. Agelou, M. Gmar, F. Lainé, J. Loridon, J-L. Ma, C. Passard, B. Poumarède Identification and differentiation of actinides inside nuclear waste packages by measurement of delayed gammas,

IEEE Trans. Nucl. Sci., vol. 57, no. 5, (2010) p. 2862

[6] D.R. Norman et al.,

Time-dependent delayed signatures from energetic photon interrogations

Nucl. Instr. Meth. B, 261 (2007) p. 316

[7] A. Lyoussi, J. Romeyer Dherbey, F. Jallu, E. Payan, A. Buisson, G. Nurdin, J. Allano

Transuranic waste assay detection by photon interrogation and on-line delayed neutron counting

Nucl. Inst. Meth. B, 160 (2000), p. 280

[8] Inventaire national des matières et déchets radioactifs- Catalogue descriptif des familles Andra (2015)

https://www.andra.fr/download/site-principal/document/editions/559.pdf

[9] D. B. Pelowitz et al.,

MCNPX 2.7.0 extensions

LA-UR-11-02295, Los Alamos National Laboratory (2011)

[10] M.B. Chadwick et al.

ENDF/B-VII.0: Next Generation Evaluated Nuclear Data Library for Nuclear Science and Technology Nuclear Data Sheets 107 (2006) 2931-3060

[11] M. Gmar, J. M. Capdevila,

Use of delayed gamma spectra for detection of actinides $(\mathrm{U}, \mathrm{Pu})$ by photofission,

Nucl. Inst. Meth. A, 422 (1999), p. 841

[12] E.T.E. Reedy, S.J. Thompson, A.W. Hunt

The detection of delayed $\gamma$-rays between intense Bremsstrahlung pulses for discriminating fissionable from non-fissionable materials

Nucl. Inst. Meth. A, 606 (2009), p. 811

[13] F. Jallu, A. Lyoussi, E. Payan, H. Recroix, A. Mariani, G. Nurdin, A. Buisson, J. Allano Photoneutron production in tungsten, praseodymium, copper and beryllium by using high energy electron linear accelerator, Nucl. Inst. Meth. B, 155 (1999) p 373

[14] Handbook on photonuclear data for applications. Cross sections and spectra. (March 2000). IAEA Photonuclear Data Library - Cross sections and spectra up to $140 \mathrm{MeV}$

[15] G. Gilmore,

Practical gamma-ray spectrometry, second edition, Wiley (2008).

[16] C. Robert-Coutant, V. Moulin, R. Sauze, P. Rizo, J.M. Casagrande, Estimation of the matrix attenuation in heterogeneous radioactive waste drums using dual-energy computed tomography

Nucl. Inst. Meth. A, 422 (1999), p. 949

[17] R. T. Bernardi and H.E. Martz

Nuclear waste drum characterization with $2 \mathrm{MeV}$ x-ray and gamma-ray tomography, Proc. SPIE 2519, X-Ray and Ultraviolet Sensors and Applications, 140 (June 15, 1995) 
1 [18] N. Estre, D. Eck, J-L. Pettier, E. Payan, C. Roure, E. Simon

2 High-energy X-ray imaging applied to nondestructive characterization of large nuclear waste 3 drums.

4 IEEE Trans. Nucl. Sci., vol. 62, no. 6, (2015) p. 3104

[19] M. Agelou, F. Carrel, M. Gmar, F. Laine, B. Poumarede, F. Tola

Photofission tomography of nuclear waste packages

8 IEEE Nuclear Science Symposium Conference Record, NSS ‘07 (2007), p 801

[20] M. Gmar, F. Jeanneau, F. Lainé, B. Poumarède

11 Photofission tomography of nuclear waste packages

12 Nucl. Inst. Meth. A, 562, issue 2, (2006) p. 1089 